OPEN ACCESS

Edited by:

Anjan Debnath,

University of California, San Diego,

United States

Reviewed by:

Derek Parsonage,

Wake Forest School of Medicine,

United States

Andrea llari,

Istituto di Biologia e Patologia

Molecolari (CNR), Italy

${ }^{*}$ Correspondence:

Bernard P. Arulanandam

bernard.arulanandam@utsa.edu

Specialty section:

This article was submitted to Antimicrobials, Resistance

and Chemotherapy,

a section of the journal

Frontiers in Microbiology

Received: 09 December 2017

Accepted: 12 February 2018

Published: 05 March 2018

Citation:

May HC, Yu J-J, Guentzel MN,

Chambers JP, Cap AP and Arulanandam BP (2018) Repurposing

Auranofin, Ebselen, and PX-12 as Antimicrobial Agents Targeting

the Thioredoxin System.

Front. Microbiol. 9:336.

doi: 10.3389/fmicb.2018.00336

\section{Repurposing Auranofin, Ebselen, and PX-12 as Antimicrobial Agents Targeting the Thioredoxin System}

\author{
Holly C. May',2, Jieh-Juen Yu ${ }^{1,2}$, M. N. Guentzel ${ }^{1,2}$, James P. Chambers ${ }^{1,2}$, \\ Andrew P. Cap ${ }^{3}$ and Bernard P. Arulanandam ${ }^{1,2 *}$ \\ ${ }^{1}$ South Texas Center for Emerging Infectious Disease, University of Texas at San Antonio, San Antonio, TX, United States, \\ ${ }^{2}$ Center for Excellence in Infection Genomics, University of Texas at San Antonio, San Antonio, TX, United States, \\ ${ }^{3}$ United States Army Institute for Surgical Research, San Antonio Military Medical Center, San Antonio, TX, United States
}

As microbial resistance to drugs continues to rise at an alarming rate, finding new ways to combat pathogens is an issue of utmost importance. Development of novel and specific antimicrobial drugs is a time-consuming and expensive process. However, the re-purposing of previously tested and/or approved drugs could be a feasible way to circumvent this long and costly process. In this review, we evaluate the U.S. Food and Drug Administration tested drugs auranofin, ebselen, and PX-12 as antimicrobial agents targeting the thioredoxin system. These drugs have been shown to act on bacterial, fungal, protozoan, and helminth pathogens without significant toxicity to the host. We propose that the thioredoxin system could serve as a useful therapeutic target with broad spectrum antimicrobial activity.

Keywords: thioredoxin, antimicrobial, antimicrobial resistance, flavoenzyme, drug target

\section{INTRODUCTION}

Resistance to antimicrobial drugs is an increasingly important public health concern leading to increased mortality, morbidity, and cost of care for affected patients. Thus, discovery of novel drug targets against drug resistant pathogens is both timely and of utmost importance. However, development of new antimicrobial agents is both time-consuming and expensive, but the repurposing of previously tested and/or approved drugs as antimicrobial therapeutic agents may be a potentially useful alternative (Ashburn and Thor, 2004). This review examines data supporting targeting of the thioredoxin system as a mechanism leading to broad spectrum antimicrobial activity against multiple species of bacteria, fungi, and eukaryotic parasites using drugs previously tested by the U.S. Food and Drug Administration (FDA).

Thioredoxins (TrxA, TrxC, Trx1, Trx2, and $\operatorname{Trx} 3$ ) are small redox proteins that possess a highly conserved active site (cys-x-x-cys) (Holmgren, 1985, 1995) referred to as the "thioredoxin motif" which consists of four $\alpha$-helices and five $\beta$-sheets (Holmgren, 1995). The thioredoxin system is an efficient disulfide reduction system, consisting of two proteins: thioredoxin, the flavoenzyme thioredoxin reductase (TrxR, Trr1, and Trr2), plus the reducing agent nicotinamide adenine dinucleotide phosphate (NADPH). These ubiquitous proteins are found in all forms of life and they, along with the glutathione/glutathione reductase (GSH/GR) are responsible for maintaining a reduced cellular environment (Holmgren, 1985).

Although highly conserved, there are notable differences in thioredoxin reductase. In humans and some protozoans, a high-molecular weight thioredoxin reductase ( $\mathrm{H}-\mathrm{TrxR})$ is present while in bacteria, fungi, plants, and some protozoa, a low-molecular weight thioredoxin reductase (L-TrxR) is observed (McMillan et al., 2009). While both forms contain a redox active disulfide adjacent to a flavin ring, the transfer of the reducing equivalents from the 
flavin ring to the protein substrate have distinct mechanisms. For an in-depth analysis on these differences, refer to the review by Williams et al. (2000). Figures 1A,B show the differences in structure and electron transfer between H-TrxR and L-TrxR. Together, these differences allow L-TrxR containing thioredoxin systems to be a potential antimicrobial target. To that end, we review the function of thioredoxin in bacteria, fungi, protozoa, and helminths, and examine some current thioredoxin system inhibitors as potential antimicrobial agents.

\section{Global Functions of Thioredoxin}

The thioredoxin system functions as a potent reducer of disulfide bonds. Disulfide bond reduction is initiated by a nucleophilic attack of the first cysteine of the twin cysteine motif on the disulfide of the target protein leading to formation of a mixed disulfide bond between thioredoxin and the target protein. Subsequently, the second cysteine nucleophilically attacks the mixed disulfide, forming an intramolecular disulfide bond in thioredoxin fully reducing the target protein (Roos et al., 2009). In turn, thioredoxin is reduced by thioredoxin reductase using NADPH as source of electrons (Lu and Holmgren, 2014). In all organisms studied to date, the thioredoxin system plays an important role in keeping the intracellular compartment in a reduced state which has been shown to be important in preventing protein aggregation (Holmgren, 1984; Stewart et al., 1998). Additionally, thioredoxin acts as a hydrogen donor for key enzymes involved in various cellular functions. Examples of these enzymes include ribonucleotide reductase, an essential enzyme during DNA synthesis (Reichard, 1993), and methionine sulfoxide reductase which plays an important role in protein repair (Gonzalez Porque et al., 1970; Boschi-Muller et al., 2000). Thioredoxin also is a hydrogen donor for phosphoadenosinephosphosulfate reductase (Lillig et al., 1999; Chartron et al., 2007) which is implicated in sulfur assimilation, and required for de novo cysteine biosynthesis in fungi and many enteric bacteria (Gonzalez Porque et al., 1970; Russel et al., 1990).

\section{Drug Characteristics}

Arguably the best studied inhibitor of the thioredoxin system is auranofin, a gold complex originally approved to treat rheumatoid arthritis (Bombardier et al., 1986). Although thioredoxin reductase may not be the sole target for auranofin (Thangamani et al., 2016a), the drug is believed to inhibit this enzyme by irreversibly binding thiol and selenol groups on the enzyme (Fan et al., 2014). Ebselen is an organoselenium drug that acts as an antioxidant and an anti-inflammatory agent due to its GSH peroxidase-like activity (Muller et al., 1984; Schewe, 1995), and is a potent bacterial TrxR inhibitor via its binding to the C-terminal active site cysteine residue ( $\mathrm{Lu}$ et al., 2013). 1-Methylpropyl 2-imidazolyl disulfide (PX-12) irreversibly binds to the Cys73 cysteine residue that lies outside the conserved redox catalytic site of Trx1 (Kirkpatrick et al., 1998). Initially tested as an antitumor drug, it was not approved due to lack of efficacy in human trials; although, it exhibited low toxicity (Ramanathan et al., 2011). Like most commonly used antibiotics, the common side effects of auranofin and PX-12 include nausea, lack of appetite, diarrhea, and stomach cramps (Furst, 1983; Cunha, 2001; Ramanathan et al., 2011). Ebselen has not shown
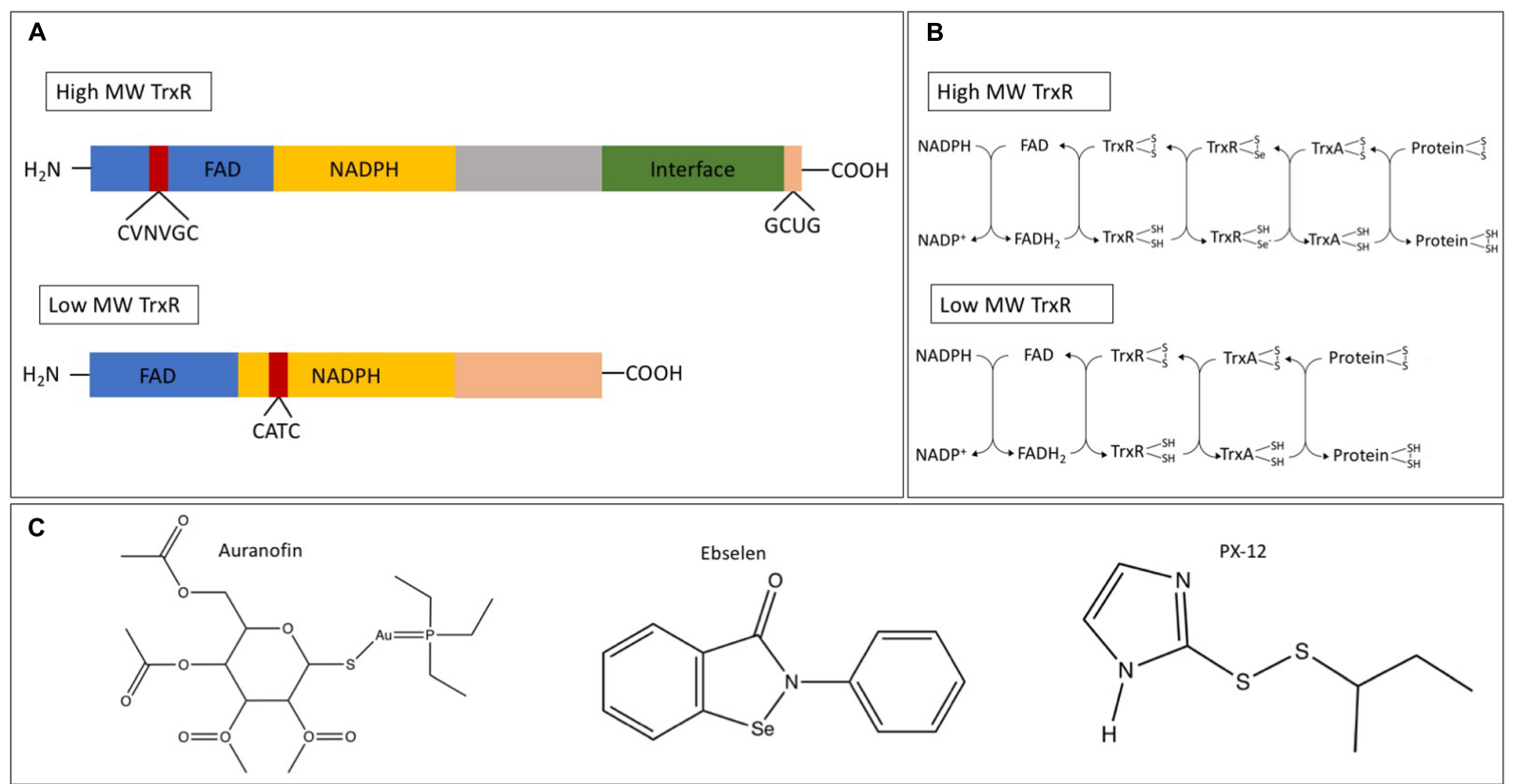

FIGURE 1 | (A) Example of the protein structure of the high (Homo sapiens) and low (Escherichia coli) molecular weight thioredoxin reductase. Shown are the flavin-adenine dinucleotide (FAD) and nicotinamide adenine dinucleotide phosphate (NADPH) binding domains, the 'central' domain, and the C-terminal domain that provides the dimer interface and part of the active site. (B) Differential electron transfer between high and low molecular weight TrxR. (C) Chemical structures of the thioredoxin system inhibitors auranofin, ebselen, and PX-12. Panels (A,B) adapted from Lu and Holmgren (2014). 
TABLE 1 | In vivo and in vitro studies of thioredoxin system inhibitors.

\begin{tabular}{|c|c|c|c|c|}
\hline Inhibitor & Pathogen & Strain & Model & Reference \\
\hline Auranofin & S. aureus & MW2 & C. elegans & Fuchs et al., 2016 \\
\hline Auranofin & S. aureus (MRSA) & Sanger 252 & Murine-systemic & Harbut et al., 2015 \\
\hline Auranofin & S. aureus (MRSA) & 132 & Murine & Aguinagalde et al., 2015 \\
\hline Auranofin & C. neoformans & Clinical isolate & C. elegans & Thangamani et al., 2017b \\
\hline Auranofin & T. gondii & $\mathrm{RH}$ & Chicken embryo & Andrade et al., 2014 \\
\hline \multirow[t]{2}{*}{ Auranofin } & G. lamblia & WB, 106, 1279 & Murine & Tejman-Yarden et al., 2013 \\
\hline & & WB & Gerbil & \\
\hline Auranofin & T. foetus & D1 & Murine - vaginal & Hopper et al., 2016 \\
\hline Ebselen & S. aureus & USA300 & Murine-skin & Thangamani et al., 2015 \\
\hline Ebselen & E. coli & $Z Y-1$ & Murine-systemic & Zou et al., 2017 \\
\hline Ebselen & C. berghei & K173 & Murine & Huther et al., 1989 \\
\hline$P X-12$ & A. fumigatus & AF-dsRed & Murine-corneal & Leal et al., 2012 \\
\hline \multirow[t]{13}{*}{ Auranofin } & S. aureus & MW2 & In vivo & Fuchs et al., 2016 \\
\hline & E. faecium & 2421 & & \\
\hline & K. pneumoniae & 77326 & & \\
\hline & A. baumannii & ATCC 17978 & & \\
\hline & $P$. aeruginosa & PA14 & & \\
\hline & Enterobacter sp. & KCTC 2625 & & \\
\hline & B. subtilis & PY 79 & & \\
\hline & E. faecalis & MMH 594 & & \\
\hline & C. albicans & SC5314 (CAN14) & & \\
\hline & C. glabrata & ATCC 90030 & & \\
\hline & Candida parapsilosis & ATCC 22019 & & \\
\hline & C. tropicalis & ATCC 13803 & & \\
\hline & C. neoformans & $\mathrm{KN} 99 \alpha$ & & \\
\hline \multirow[t]{10}{*}{ Auranofin } & M. tuberculosis & H37Ra & In vivo & Harbut et al., 2015 \\
\hline & B. subtilis & 168, PY79 & & \\
\hline & S. aureus (MRSA) & Sanger 252, TCH1516, ST-59, A7819, PA, D712 & & \\
\hline & & A5940, X18311, PC-3, HIP 5836 & & \\
\hline & S. aureus & MSSA 29213 & & \\
\hline & E. faecium (VRE) & VRE8 WMC, VRE 12-15-19 UCLA & & \\
\hline & E. faecalis & Belt & & \\
\hline & K. pneumoniae & 1100 & & \\
\hline & A. baumannii & ATCC 19606, ATCC 17978, 5075 & & \\
\hline & P. aeruginosa & PA01, PA103 & & \\
\hline Auranofin & E. histolytica & HM1:IMSS & In vivo & Debnath et al., 2012 \\
\hline Auranofin & P. falciparum & 3D7 & In vivo & Sannella et al., 2008 \\
\hline Auranofin & L. infantum & MHOM/TN/80/IPT1 & In vivo & Ilari et al., 2012 \\
\hline Auranofin & T. brucei & 449 & In vivo & Lobanov et al., 2006 \\
\hline Auranofin & E. granulosus & Clinical isolate & In vivo & Bonilla et al., 2008 \\
\hline \multirow[t]{4}{*}{ Auranofin } & E. coli & ATCC 25922 & & \\
\hline & S. aureus & ATCC 25923, USA300 & In vivo & Cassetta et al., 2014 \\
\hline & $\begin{array}{l}\text { Staphylococcus } \\
\text { epidermidis }\end{array}$ & ATCC 35984, ATCC 12228 & & \\
\hline & MRSA & Five clinical isolates & & \\
\hline \multirow[t]{4}{*}{ Auranofin } & $P$. aeruginosa & $\mathrm{n} / \mathrm{a}$ & In vivo & Hokai et al., 2014 \\
\hline & E. coli & $\mathrm{n} / \mathrm{a}$ & & \\
\hline & S. aureus & USA300 & & \\
\hline & S. cerevisiae & USA400 & & \\
\hline \multirow[t]{4}{*}{ Auranofin } & C. albicans & $\mathrm{CA}-1$ to $\mathrm{CA}-13$ & In vivo & Wiederhold et al., 2017 \\
\hline & C. glabrata & CG-1 to CG-10 & & \\
\hline & Candida krusei & QC & & \\
\hline & C. parapsilosis & QC, $\mathrm{CP}-1$ to $\mathrm{CP}-10$ & & \\
\hline
\end{tabular}


TABLE 1 | Continued

\begin{tabular}{|c|c|c|c|c|}
\hline Inhibitor & Pathogen & Strain & Model & Reference \\
\hline & C. neoformans & $\mathrm{CN}-1$ to $\mathrm{CN}-3$ & & \\
\hline & Blastomyces dermatitidis & $\mathrm{BD}-1$ to $\mathrm{BD}-3$ & & \\
\hline & Paecilomyces variotii & QC & & \\
\hline & A. fumigatus & $A F-1$ to $A F-3$ & & \\
\hline & Rhizopus oryzae & $\mathrm{R}-1$ to $\mathrm{R}-3$ & & \\
\hline & S. apiospermum & SA-1 to SA-7 & & \\
\hline & L. prolificans & $\mathrm{SP}-1$ to SP-6 & & \\
\hline Auranofin & S. aureus & $\mathrm{TCH} 1516$ & In vivo & Torres et al. (2016) \\
\hline Auranofin & T. gondii & $\mathrm{RH}$ & In vivo & Andrade et al., 2014 \\
\hline Auranofin & C. albicans & SC5314 & In vivo & Siles et al., 2013 \\
\hline \multirow[t]{6}{*}{ Ebselen } & E. coli & DHB4 & In vivo & Lu et al. (2013) \\
\hline & H. pylori & MSG6, MSG142, MR162 & & \\
\hline & & MRG193, NCTC11637, YS-16 & & \\
\hline & M. tuberculosis & $\mathrm{H} 37 \mathrm{Rv}$ & & \\
\hline & & Panel 3:24 & & \\
\hline & & ВТВ98-310 & & \\
\hline \multirow[t]{10}{*}{ Ebselen } & S. aureus (MRSA) & USA100, USA200, USA300 & In vivo & Thangamani et al., 2015 \\
\hline & & USA400, USA500, USA700 & & \\
\hline & & USA800, USA1000, USA1100 & & \\
\hline & & ATCC 43300, ATCC BAA-44 & & \\
\hline & Linezolid-resistant SA & NRS119 & & \\
\hline & Mupirocin-resistant SA & NRS 107 & & \\
\hline & Vancomycin-resistant SA & VRS1-VRS3a, VRS3b & & \\
\hline & & VRS4-VRS10 & & \\
\hline & S. epidermidis & NRS101 & & \\
\hline & S. aureus & ATCC 6538 & & \\
\hline \multirow[t]{4}{*}{ Ebselen } & B. subtilis & ATCC 6633 & In vivo & Gustafsson et al., 2016 \\
\hline & S. aureus & ATCC 29213 & & \\
\hline & Bacillus cereus & ATCC 14579 & & \\
\hline & M. tuberculosis & H37Rv & & \\
\hline \multirow[t]{7}{*}{ Ebselen } & S. aureus & ATCC 25923 & In vivo & Pietka-Ottlik et al., 2008 \\
\hline & Staphylococcus simulans & $103 \mathrm{P}$ & & \\
\hline & E. coli & ATCC 25922 & & \\
\hline & P. aeruginosa & ATCC 258243 & & \\
\hline & K. pneumoniae & ATCC 700603 & & \\
\hline & Aspergillus niger & Filamentous & & \\
\hline & C. albicans & Yeast & & \\
\hline \multirow[t]{6}{*}{ Ebselen } & E. coli & DHB4, ZY-1, ATCC 700926 & In vivo & Zou et al., 2017 \\
\hline & & 1139,2219 & & \\
\hline & K. pneumoniae & 322 & & \\
\hline & A. baumannii & $H, 361$ & & \\
\hline & P. aeruginosa & 1298,9 & & \\
\hline & Enterobacter cloacae & 431,2301 & & \\
\hline Ebselen & S. cerevisiae & $\mathrm{AH} 109$ & In vivo & Billack et al., 2010 \\
\hline \multirow[t]{7}{*}{ Ebselen } & Aspergillus flavus & ATCC MYA-3631 & In vivo & Ngo et al., 2016 \\
\hline & Aspergillus terreus & ATCC MYA-3633 & & \\
\hline & Aspergillus nidulans & ATCC 38163 & & \\
\hline & C. albicans & $\begin{array}{l}\text { ATCC 10231, 64124, MYA-2876, MYA-90819, } \\
\text { MYA-1003, MYA-2310, ATCC } 1237\end{array}$ & & \\
\hline & C. glabrata & ATCC 2001 & & \\
\hline & C. krusei & ATCC 6258 & & \\
\hline & C. parapsilosis & ATCC 22019 & & \\
\hline Ebselen & P. falciparum & T996 & In vivo & Huther et al., 1989 \\
\hline$P X-12$ & A. fumigatus & AF-bp & In vivo & Leal et al., 2012 \\
\hline
\end{tabular}


adverse effects at the recommended dose (Singh et al., 2016). Please see Table 1 for a list of pathogens these drugs have been tested against. For chemical structures of these inhibitors, see Figure 1C.

\section{Bacterial Thioredoxin}

In general, bacterial thioredoxin systems are encoded by a single thioredoxin reductase, and two thioredoxin genes. The best studied system is that of Escherichia coli which has two thioredoxins, a higher expressed $\operatorname{Trx} 1$ protein (encoded by $\operatorname{Tr} x A$ ) with greater electron donor efficacy and a less expressed TrxC which contains two additional $\mathrm{c}-\mathrm{x}$ - $\mathrm{x}-\mathrm{c}$ motifs at its $\mathrm{N}$-terminus (Laurent et al., 1964; Miranda-Vizuete et al., 1997). As shown by gene deletion, neither of these thioredoxin genes are required for viability in $E$. coli (Ritz et al., 2000). However, some bacteria, such as Rhodobacter sphaeroides (Pasternak et al., 1997), Bacillus subtilis (Scharf et al., 1998), and Anacystis nidulans (Muller and Buchanan, 1989) require a bacterial thioredoxin gene for survival. Redundant to the thioredoxin system in many bacteria is the glutaredoxin system which was initially identified as an alternative hydrogen donor for ribonucleotide reductase in an E. coli thioredoxin mutant (Holmgren, 1976). Simultaneous disruption of both thioredoxin and glutaredoxin systems is often lethal for bacteria (Prinz et al., 1997; Stewart et al., 1998). To date, it appears most Gram-negative bacteria contain both a thioredoxin and GSH system while most Gram-positive bacteria contain only a thioredoxin system (Lu and Holmgren, 2014). This highlights the critical role of thiol-redox homeostasis for microbial growth and further underscores antimicrobial drug potential.

Bacterial thioredoxin function and gene regulation has been reviewed previously (Zeller and Klug, 2006; Lu and Holmgren, 2014). Recent reports from animal studies have shed additional light on the important role of thioredoxin in bacterial pathogenesis. Cheng et al. (2017) propose that TrxA is essential for maintaining a highly reduced environment in the cytosol of Listeria monocytogenes providing a favorable environment for protein folding and subsequent activation. Furthermore, it was observed that $\operatorname{TrxA}$ is required for proper function of several key regulators, including (1) MogR, a DNA binding transcriptional repressor involved in flagella formation, and (2) PrfA, a member of the cAMP receptor protein (Crp) family of transcription factors which regulates several major virulence factors (ActA, LLO, and Hpt) of Listeria. Deletion of the TrxA gene in Listeria resulted in loss of motility and impairment of hemolytic activity greatly reducing virulence of this pathogen in mice.

Thioredoxin also has been shown to play a role in the virulence of Helicobacter pylori which uses secreted thioredoxin to reduce mucin molecules to their monomeric form decreasing mucin viscosity and allowing the organism to colonize as well as facilitating migration to the epithelial surface (Windle et al., 2000). Deletion of either the TrxA or TrxC genes in H. pylori impairs the organism's ability to colonize the stomach following oral bacterial challenge (Kuhns et al., 2015).

Lin et al. (2016), while studying a Mycobacterium tuberculosis thioredoxin reductase (TrxB2) mutant, observed TrxB2 to be an essential thiol-reducing enzyme in vitro, and its deficiency lead to increased clearance of the bacterium during both the acute and chronic phases of infection. Importantly, TrxB2 depletion resulted in hyper-susceptibility to rifampin, a frontline antituberculosis drug, suggesting that a thioredoxin inhibitor can be used in combination with other existing antibiotics for better control of bacterial infection. This could be of significant therapeutic value in treatment of multi-drug resistant bacteria when choice of available antibiotics is limited.

Auranofin has been tested in both Gram-positive and Gram-negative bacteria. Auranofin exhibited a lower minimum inhibitory concentration (MIC) for Gram-positive pathogens than for Gram-negative, likely due to (1) the presence of the redundant GSH system (Cassetta et al., 2014; Harbut et al., 2015; Fuchs et al., 2016), and (2) the impermeability of the drug through the outer membrane (Thangamani et al., 2016a). Using an in vitro enzymatic assay, Harbut et al. (2015) clearly demonstrated that auranofin inhibited both recombinant thioredoxin reductases of M. tuberculosis and Staphylococcus aureus, by reducing bacterial cellular free thiols, leading to compromised defense against oxidative stress.

Auranofin was also tested against medically relevant drug resistant pathogens collectively referred to as "ESKAPE" pathogens. This grouping includes Enterococcus faecium, S. aureus, Klebsiella pneumoniae, Acinetobacter baumannii, Pseudomonas aeruginosa, and Enterobacter species. Auranofin was found to inhibit $S$. aureus, E. faecium, and A. baumannii in bacteriostatic fashion at the MIC, but bactericidal at higher concentrations (Fuchs et al., 2016). A number of studies using S. aureus have recognized auranofin as a potent antibacterial compound. Using an in vivo Caenorhabditis elegans infection model, auranofin was shown to be protective against $S$. aureus, Enterococcus faecalis, and E. faecium via apparent targeting of the thioredoxin system (Fuchs et al., 2016). Auranofin and other related gold-compounds also were shown to exhibit significant inhibition against methicillin-resistant S. aureus (MRSA) (Hokai et al., 2014). Animal studies carried out using mouse models further demonstrate the potential usefulness of auranofin against cutaneous (Thangamani et al., 2016b) and implant-associated biofilm (Aguinagalde et al., 2015) infections by MRSA.

Ebselen and ebselen analogs have bactericidal effects against MRSA, E. coli, and H. pylori by blocking electron transfer to thioredoxin (Lu et al., 2013). Similar to auranofin, ebselen is highly active against bacteria lacking GSH production, e.g., S. aureus, H. pylori, M. tuberculosis, and Bacillus anthracis (Lu et al., 2013; Gustafsson et al., 2016), but less effective against Gram-negative bacteria (Pietka-Ottlik et al., 2008). Simultaneous blockage of both thioredoxin and glutaredoxin systems has been explored by Zou et al. (2017) using ebselen and silver nitrate for treatment of Gram-negative bacterial infection. These results demonstrated that silver in the presence of ebselen directly inhibited E. coli thioredoxin reductase, and rapidly depleted GSH resulting in elevated reactive oxygen species (ROS) production and impaired DNA synthesis leading to bacterial death. Additionally, combined treatment significantly improved survival from sepsis by $E$. coli during murine infection. In a recent study using S. aureus by Thangamani et al. (2015), 
ebselen was demonstrated to greatly reduce (1) toxin (PantonValentine leukocidin and $\alpha$-hemolysin) production, (2) biofilm formation in vitro, and (3) with topical treatment of skin infection significantly reduced bacterial loads accompanied with a decreased inflammatory response.

\section{Fungal Thioredoxin}

Saccharomyces cerevisiae contains both cytoplasmic and mitochondrial thioredoxin systems. Under normal growth conditions, cytoplasmic thioredoxins (Trx1 and Trx2) are both dispensable; however, simultaneous deletion of both thioredoxins slowed the rate of DNA synthesis leading to abnormal cell cycle (Muller, 1991). Thioredoxin has also been shown to function in a protective manner against ROS in S. cerevisiae (Kuge and Jones, 1994; Muller, 1996) as well as medically important fungi such as Candida albicans (da Silva Dantas et al., 2010) and Aspergillus nidulans (Thon et al., 2007). The yeast mitochondrial thioredoxin system, which includes a thioredoxin (Trx3) and thioredoxin reductase (Trr2), protects against oxidative stress generated during respiratory metabolism (Pedrajas et al., 1999). However, it does not appear that this mitochondrial system can substitute for the cytoplasmic thioredoxin or glutaredoxin systems, as its presence does not ameliorate the slowing of the cell cycle when Trx1 and Trx2 genes are deleted (Draculic et al., 2000). Fungal thioredoxin reductases are of the low molecular weight protein type with an overall folding structure similar to bacterial TrxR (Zhang et al., 2009). Strains lacking Trr1 gene are hypersensitive to hydrogen peroxide, temperature sensitive for growth, and have an auxotrophic requirement for methionine (Machado et al., 1997; Pearson and Merrill, 1998). Trr1 is most likely essential in C. albicans as a true Trr1 gene knock out could not be created; however, heterozygous strains of $C$. albicans are more sensitive to oxidative stress and exhibit a decreased pathogenicity compared to the wild-type (Zaki et al., 2012). Similarly, Trr1 was shown to be essential to Cryptococcus neoformans viability (Missall and Lodge, 2005).

In vitro auranofin inhibited medically relevant Aspergillus fumigatus, Candida tropicalis, Candida glabrata, and C. albicans, and was shown to have high efficacy against fluconazole resistant C. albicans as well as the hard-to-treat fungal pathogens Scedosporium apiospermum and Lomentospora prolificans (Fuchs et al., 2016; Wiederhold et al., 2017). Additionally, auranofin exhibited significant inhibition of C. albicans biofilm formation (Siles et al., 2013), and was shown to protect against C. neoformans infection in an in vivo C. elegans model (Thangamani et al., 2017b).

Ebselen has been shown to be effective against $S$. cerevisiae as well as fluconazole-resistant C. albicans (Billack et al., 2010). Additionally, ebselen analogs are effective against C. albicans and Aspergillus spp. (Pietka-Ottlik et al., 2008; Ngo et al., 2016). A recent study by Thangamani et al. (2017a), demonstrated that ebselen regulates fungal GSH and ROS production, and is a potent antifungal drug against clinically relevant isolates of both Candida and Cryptococcus in a C. elegans infection model.

PX-12 was tested against the filamentous fungus $A$. fumigatus, and lead to increase fungal hyphae sensitivity to both $\mathrm{H}_{2} \mathrm{O}_{2}$ and neutrophil-mediated killing in vitro. Furthermore, topical PX-12 treatment significantly enhanced neutrophil-mediated fungal killing in infected mouse corneas (Leal et al., 2012).

\section{Protozoa and Helminth Thioredoxin Systems}

Like bacteria, protozoans contain either a thioredoxin system or a combination of thioredoxin and GSH systems. Entamoeba histolytica, Trichomonas vaginalis, and Giardia lamblia all possess a thioredoxin system, consisting of thioredoxin (Trx), Trx peroxidase, and an L-TrxR (Hughes et al., 2003; Coombs et al., 2004; Arias et al., 2007; Leitsch et al., 2009). Plasmodium falciparum possesses both GSH/GR and Trx/TrxR redox systems (Kawazu et al., 2001; Nickel et al., 2006; Kehr et al., 2010); however, loss of TrxR results in loss of viability in this pathogen (Theobald et al., 2012).

Genome sequencing of Trypanosoma brucei (Berriman et al., 2005), Trypanosoma cruzi (El-Sayed et al., 2005), and Leishmania major (Ivens et al., 2005) demonstrated that trypanosomatids lack genes for GSH/GR and Trx/TrxR. Instead, they rely on trypanothione, a GSH derivate, and trypanothione reductase (TryR) to maintain disulfides in a reduced form (Fairlamb et al., 1985; Fairlamb and Cerami, 1992).

TrxR also has been shown to be a virulence factor in Toxoplasma gondii. Deletion of T. gondii TrxR gene reduced the parasite's antioxidant capacity, invasion efficiency, and proliferation significantly prolonging the survival time of mice infected with the gene-knockout parasite as compared to the wild-type strain of parasite (Xue et al., 2017). Flatworms of the class Cestoda and Trematoda possess a single flavoenzyme for both thioredoxin and GSH, and is referred to as thioredoxin GSH reductase (TGR; Ross et al., 2012). Schistosoma mansoni depends totally on TGR for thiol redox homeostasis. Auranofin binds to TGR leading to reduced worm burdens in vivo (Angelucci et al., 2010). Inhibitors of TGR will not be covered further in this review.

The antimicrobial drug metronidazole (Flagyl) depends upon reduction by a flavoenzyme to become active. Resistance to this drug has been associated with changes in amounts of flavoenzymes produced by parasites (Wassmann et al., 1999; Leitsch et al., 2010, 2011). Since metronidazole does not directly inhibit the thioredoxin system, it will not be discussed further in this review.

Auranofin has also been shown to be effective in protection against protozoa and helminthes. E. histolytica trophozoites were observed to be 10 times more sensitive to auranofin than to metronidazole (Debnath et al., 2012). Auranofin blocked thioredoxin reductase in multiple strains of metronidazole resistant G. lamblia, as well as greatly reducing the number of trophozoites in the small intestine of orally challenged newborn and adult mice and gerbils (Tejman-Yarden et al., 2013). Auranofin also has been shown to have potent antimicrobial effects both in vivo and in vitro against T. gondii (Andrade et al., 2014). Oral administration of auranofin for 4 days cleared Tritrichomonas foetus in a murine model of vaginal infection (Hopper et al., 2016). Auranofin has also been shown to inhibit the growth of $P$. falciparum 
(Sannella et al., 2008), the pro-mastigote stage of Leishmania infantum (Ilari et al., 2012), the blood stream and procyclic stages of T. brucei (Lobanov et al., 2006), as well as Echinococcus granulosus larvae (Bonilla et al., 2008).

Treatment of protozoan and helminth infections with ebselen has not been widely explored. However, Huther et al. (1989) reported that while ebselen blocked the growth of human $P$. falciparum at all stages including the invasion of erythrocytes by merozoites using highly synchronized cultures, treatment was ineffective against murine Plasmodium berghei in a mouse infection model.

\section{CONCLUSION}

Thioredoxin is a ubiquitous redox protein found in all life forms. However, significant differences in the structure of thioredoxin reductase moieties vary among higher eukaryotes and microbes. Most importantly, all bacteria, helminths, fungi, and some protozoa contain a low molecular weight thioredoxin reductase. This differs from the high molecular weight enzyme found in mammals. Therefore, the thioredoxin system can be used as an ideal target for novel antimicrobial therapies. As drug resistance continues to grow and in the absence of introduction of new

\section{REFERENCES}

Aguinagalde, L., Diez-Martinez, R., Yuste, J., Royo, I., Gil, C., Lasa, I., et al. (2015). Auranofin efficacy against MDR Streptococcus pneumoniae and Staphylococcus aureus infections. J. Antimicrob. Chemother. 70, 2608-2617. doi: 10.1093/jac/ dkv163

Andrade, R. M., Chaparro, J. D., Capparelli, E., and Reed, S. L. (2014). Auranofin is highly efficacious against Toxoplasma gondii in vitro and in an in vivo experimental model of acute toxoplasmosis. PLOS Negl. Trop. Dis. 8:e2973. doi: 10.1371/journal.pntd.0002973

Angelucci, F., Dimastrogiovanni, D., Boumis, G., Brunori, M., Miele, A. E., Saccoccia, F., et al. (2010). Mapping the catalytic cycle of Schistosoma mansoni thioredoxin glutathione reductase by X-ray crystallography. J. Biol. Chem. 285, 32557-32567. doi: 10.1074/jbc.M110.141960

Arias, D. G., Gutierrez, C. E., Iglesias, A. A., and Guerrero, S. A. (2007). Thioredoxin-linked metabolism in Entamoeba histolytica. Free Radic. Biol. Med. 42, 1496-1505. doi: 10.1016/j.freeradbiomed.2007. 02.012

Ashburn, T. T., and Thor, K. B. (2004). Drug repositioning: identifying and developing new uses for existing drugs. Nat. Rev. Drug Discov. 3, 673-683. doi: $10.1038 / \mathrm{nrd} 1468$

Berriman, M., Ghedin, E., Hertz-Fowler, C., Blandin, G., Renauld, H., Bartholomeu, D. C., et al. (2005). The genome of the African trypanosome Trypanosoma brucei. Science 309, 416-422. doi: 10.1126/science.11 12642

Billack, B., Pietka-Ottlik, M., Santoro, M., Nicholson, S., Mlochowski, J., and Lau-Cam, C. (2010). Evaluation of the antifungal and plasma membrane $\mathrm{H}+$-ATPase inhibitory action of ebselen and two ebselen analogs in S. cerevisiae cultures. J. Enzyme Inhib. Med. Chem. 25, 312-317. doi: 10.3109/ 14756360903179419

Bombardier, C., Ware, J., Russell, I. J., Larson, M., Chalmers, A., and Read, J. L. (1986). Auranofin therapy and quality of life in patients with rheumatoid arthritis. Results of a multicenter trial. Am. J. Med. 81, 565-578. doi: 10.1016/ 0002-9343(86)90539-5

Bonilla, M., Denicola, A., Novoselov, S. V., Turanov, A. A., Protasio, A., Izmendi, D., et al. (2008). Platyhelminth mitochondrial and cytosolic redox homeostasis is controlled by a single thioredoxin glutathione reductase and antimicrobials, the repurposing of currently available drugs may constitute a new and viable therapeutic approach.

Currently, FDA tested drugs targeting the thioredoxin system include PX-12, auranofin, and ebselen. These drugs have shown antimicrobial effects in a variety of organisms (Table 1). The repurposing of these previously approved drugs could allow for better treatment options, including synergistic effects with existing antimicrobial drugs, against microbial infections.

\section{AUTHOR CONTRIBUTIONS}

All authors have made a substantial and intellectual contribution to publish this review article. BA outlined and edited the review. $\mathrm{HM}$ and J-JY searched the literature and wrote the review. MG, JC, and AC provided critique and edited the review.

\section{FUNDING}

This work was supported by National Institutes of Health Grant 1R21AI124021. Partial support of this study was from the Jane and Roland Blumberg Professorship in Biology for BA.

dependent on selenium and glutathione. J. Biol. Chem. 283, 17898-17907. doi: 10.1074/jbc.M710609200

Boschi-Muller, S., Azza, S., Sanglier-Cianferani, S., Talfournier, F., Van Dorsselear, A., and Branlant, G. (2000). A sulfenic acid enzyme intermediate is involved in the catalytic mechanism of peptide methionine sulfoxide reductase from Escherichia coli. J. Biol. Chem. 275, 35908-35913. doi: 10.1074/jbc.M006137200

Cassetta, M. I., Marzo, T., Fallani, S., Novelli, A., and Messori, L. (2014). Drug repositioning: auranofin as a prospective antimicrobial agent for the treatment of severe staphylococcal infections. Biometals 27, 787-791. doi: 10.1007/s10534014-9743-6

Chartron, J., Shiau, C., Stout, C. D., and Carroll, K. S. (2007). 3'Phosphoadenosine- $5^{\prime}$-phosphosulfate reductase in complex with thioredoxin: a structural snapshot in the catalytic cycle. Biochemistry 46, 3942-3951. doi: 10.1021/bi700130e

Cheng, C., Dong, Z., Han, X., Wang, H., Jiang, L., Sun, J., et al. (2017). Thioredoxin a is essential for motility and contributes to host infection of Listeria monocytogenes via redox interactions. Front. Cell. Infect. Microbiol. 7:287. doi: 10.3389/fcimb.2017.00287

Coombs, G. H., Westrop, G. D., Suchan, P., Puzova, G., Hirt, R. P., Embley, T. M., et al. (2004). The amitochondriate eukaryote Trichomonas vaginalis contains a divergent thioredoxin-linked peroxiredoxin antioxidant system. J. Biol. Chem. 279, 5249-5256. doi: 10.1074/jbc.M304359200

Cunha, B. A. (2001). Antibiotic side effects. Med. Clin. North Am. 85, 149-185. doi: 10.1016/S0025-7125(05)70309-6

da Silva Dantas, A., Patterson, M. J., Smith, D. A., Maccallum, D. M., Erwig, L. P., Morgan, B. A., et al. (2010). Thioredoxin regulates multiple hydrogen peroxideinduced signaling pathways in Candida albicans. Mol. Cell. Biol. 30, 4550-4563. doi: 10.1128/MCB.00313-10

Debnath, A., Parsonage, D., Andrade, R. M., He, C., Cobo, E. R., Hirata, K., et al. (2012). A high-throughput drug screen for Entamoeba histolytica identifies a new lead and target. Nat. Med. 18, 956-960. doi: 10.1038/ nm. 2758

Draculic, T., Dawes, I. W., and Grant, C. M. (2000). A single glutaredoxin or thioredoxin gene is essential for viability in the yeast Saccharomyces cerevisiae. Mol. Microbiol. 36, 1167-1174. doi: 10.1046/j.1365-2958.2000. 01948.x 
El-Sayed, N. M., Myler, P. J., Bartholomeu, D. C., Nilsson, D., Aggarwal, G., Tran, A. N., et al. (2005). The genome sequence of Trypanosoma cruzi, etiologic agent of Chagas disease. Science 309, 409-415. doi: 10.1126/science. 1112631

Fairlamb, A. H., Blackburn, P., Ulrich, P., Chait, B. T., and Cerami, A. (1985). Trypanothione: a novel bis(glutathionyl)spermidine cofactor for glutathione reductase in trypanosomatids. Science 227, 1485-1487. doi: 10.1126/science. 3883489

Fairlamb, A. H., and Cerami, A. (1992). Metabolism and functions of trypanothione in the Kinetoplastida. Annu. Rev. Microbiol. 46, 695-729. doi: 10.1146/annurev.mi.46.100192.003403

Fan, C., Zheng, W., Fu, X., Li, X., Wong, Y. S., and Chen, T. (2014). Strategy to enhance the therapeutic effect of doxorubicin in human hepatocellular carcinoma by selenocystine, a synergistic agent that regulates the ROSmediated signaling. Oncotarget 5, 2853-2863. doi: 10.18632/oncotarget. 1854

Fuchs, B. B., RajaMuthiah, R., Souza, A. C., Eatemadpour, S., Rossoni, R. D., Santos, D. A., et al. (2016). Inhibition of bacterial and fungal pathogens by the orphaned drug auranofin. Future Med. Chem. 8, 117-132. doi: 10.4155/fmc. 15.182

Furst, D. E. (1983). Mechanism of action, pharmacology, clinical efficacy and side effects of auranofin. An orally administered organic gold compound for the treatment of rheumatoid arthritis. Pharmacotherapy 3, 284-298. doi: 10.1002/j. 1875-9114.1983.tb03277.x

Gonzalez Porque, P., Baldesten, A., and Reichard, P. (1970). The involvement of the thioredoxin system in the reduction of methionine sulfoxide and sulfate. J. Biol. Chem. 245, 2371-2374.

Gustafsson, T. N., Osman, H., Werngren, J., Hoffner, S., Engman, L., and Holmgren, A. (2016). Ebselen and analogs as inhibitors of Bacillus anthracis thioredoxin reductase and bactericidal antibacterials targeting Bacillus species, Staphylococcus aureus and Mycobacterium tuberculosis. Biochim. Biophys. Acta 1860, 1265-1271. doi: 10.1016/j.bbagen.2016.03.013

Harbut, M. B., Vilcheze, C., Luo, X., Hensler, M. E., Guo, H., Yang, B., et al. (2015). Auranofin exerts broad-spectrum bactericidal activities by targeting thiol-redox homeostasis. Proc. Natl. Acad. Sci. U.S.A. 112, 4453-4458. doi: 10.1073/pnas. 1504022112

Hokai, Y., Jurkowicz, B., Fernandez-Gallardo, J., Zakirkhodjaev, N., Sanau, M., Muth, T. R., et al. (2014). Auranofin and related heterometallic gold(I)thiolates as potent inhibitors of methicillin-resistant Staphylococcus aureus bacterial strains. J. Inorg. Biochem. 138, 81-88. doi: 10.1016/j.jinorgbio.2014. 05.008

Holmgren, A. (1976). Hydrogen donor system for Escherichia coli ribonucleosidediphosphate reductase dependent upon glutathione. Proc. Natl. Acad. Sci. U.S.A. 73, 2275-2279. doi: 10.1073/pnas.73.7.2275

Holmgren, A. (1984). Enzymatic reduction-oxidation of protein disulfides by thioredoxin. Methods Enzymol. 107, 295-300. doi: 10.1016/0076-6879(84) 07019-1

Holmgren, A. (1985). Thioredoxin. Annu. Rev. Biochem. 54, 237-271. doi: 10.1146/ annurev.bi.54.070185.001321

Holmgren, A. (1995). Thioredoxin structure and mechanism: conformational changes on oxidation of the active-site sulfhydryls to a disulfide. Structure 3, 239-243. doi: 10.1016/S0969-2126(01)00153-8

Hopper, M., Yun, J. F., Zhou, B., Le, C., Kehoe, K., Le, R., et al. (2016). Auranofin inactivates Trichomonas vaginalis thioredoxin reductase and is effective against trichomonads in vitro and in vivo. Int. J. Antimicrob. Agents 48, 690-694. doi: 10.1016/j.ijantimicag.2016.09.020

Hughes, M. A., Lee, C. W., Holm, C. F., Ghosh, S., Mills, A., Lockhart, L. A., et al. (2003). Identification of Entamoeba histolytica thiol-specific antioxidant as a GalNAc lectin-associated protein. Mol. Biochem. Parasitol. 127, 113-120. doi: 10.1016/S0166-6851(02)00326-2

Huther, A. M., Zhang, Y., Sauer, A., and Parnham, M. J. (1989). Antimalarial properties of ebselen. Parasitol. Res. 75, 353-360. doi: 10.1007/BF00 931130

Ilari, A., Baiocco, P., Messori, L., Fiorillo, A., Boffi, A., Gramiccia, M., et al. (2012). A gold-containing drug against parasitic polyamine metabolism: the X-ray structure of trypanothione reductase from Leishmania infantum in complex with auranofin reveals a dual mechanism of enzyme inhibition. Amino Acids 42, 803-811. doi: 10.1007/s00726-011-0997-9
Ivens, A. C., Peacock, C. S., Worthey, E. A., Murphy, L., Aggarwal, G., Berriman, M., et al. (2005). The genome of the kinetoplastid parasite, Leishmania major. Science 309, 436-442. doi: 10.1126/science. 1112680

Kawazu, S., Komaki, K., Tsuji, N., Kawai, S., Ikenoue, N., Hatabu, T., et al. (2001). Molecular characterization of a 2-Cys peroxiredoxin from the human malaria parasite Plasmodium falciparum. Mol. Biochem. Parasitol. 116, 73-79. doi: 10. 1016/S0166-6851(01)00308-5

Kehr, S., Sturm, N., Rahlfs, S., Przyborski, J. M., and Becker, K. (2010). Compartmentation of redox metabolism in malaria parasites. PLOS Pathog. 6:e1001242. doi: 10.1371/journal.ppat.1001242

Kirkpatrick, D. L., Kuperus, M., Dowdeswell, M., Potier, N., Donald, L. J., Kunkel, M., et al. (1998). Mechanisms of inhibition of the thioredoxin growth factor system by antitumor 2-imidazolyl disulfides. Biochem. Pharmacol. 55, 987-994. doi: 10.1016/S0006-2952(97)00597-2

Kuge, S., and Jones, N. (1994). YAP1 dependent activation of TRX2 is essential for the response of Saccharomyces cerevisiae to oxidative stress by hydroperoxides. EMBO J. 13, 655-664.

Kuhns, L. G., Wang, G., and Maier, R. J. (2015). Comparative roles of the two Helicobacter pylori thioredoxins in preventing macromolecule damage. Infect. Immun. 83, 2935-2943. doi: 10.1128/IAI.00232-15

Laurent, T. C., Moore, E. C., and Reichard, P. (1964). Enzymatic synthesis of deoxyribonucleotides. iv. isolation and characterization of thioredoxin, the hydrogen donor from Escherichia Coli B. J. Biol. Chem. 239, 3436-3444.

Leal, S. M. Jr., Vareechon, C., Cowden, S., Cobb, B. A., Latgé, J. P., Momany, M., et al. (2012). Fungal antioxidant pathways promote survival against neutrophils during infection. J. Clin. Invest. 122, 2482-2498. doi: 10.1172/JC I63239

Leitsch, D., Burgess, A. G., Dunn, L. A., Krauer, K. G., Tan, K., Duchene, M., et al. (2011). Pyruvate:ferredoxin oxidoreductase and thioredoxin reductase are involved in 5-nitroimidazole activation while flavin metabolism is linked to 5-nitroimidazole resistance in Giardia lamblia. J. Antimicrob. Chemother. 66, 1756-1765. doi: 10.1093/jac/dkr192

Leitsch, D., Kolarich, D., Binder, M., Stadlmann, J., Altmann, F., and Duchene, M. (2009). Trichomonas vaginalis: metronidazole and other nitroimidazole drugs are reduced by the flavin enzyme thioredoxin reductase and disrupt the cellular redox system. Implications for nitroimidazole toxicity and resistance. Mol. Microbiol. 72, 518-536. doi: 10.1111/j.1365-2958.2009.0 6675.x

Leitsch, D., Kolarich, D., and Duchene, M. (2010). The flavin inhibitor diphenyleneiodonium renders Trichomonas vaginalis resistant to metronidazole, inhibits thioredoxin reductase and flavin reductase, and shuts off hydrogenosomal enzymatic pathways. Mol. Biochem. Parasitol. 171, 17-24. doi: 10.1016/j.molbiopara.2010.01.001

Lillig, C. H., Prior, A., Schwenn, J. D., Aslund, F., Ritz, D., Vlamis-Gardikas, A., et al. (1999). New thioredoxins and glutaredoxins as electron donors of $3^{\prime}$ phosphoadenylylsulfate reductase. J. Biol. Chem. 274, 7695-7698. doi: 10.1074/ jbc. 274.12 .7695

Lin, K., O’Brien, K. M., Trujillo, C., Wang, R., Wallach, J. B., Schnappinger, D., et al. (2016). Mycobacterium tuberculosis thioredoxin reductase is essential for thiol redox homeostasis but plays a minor role in antioxidant defense. PLOS Pathog. 12:e1005675. doi: 10.1371/journal.ppat.1005675

Lobanov, A. V., Gromer, S., Salinas, G., and Gladyshev, V. N. (2006). Selenium metabolism in Trypanosoma: characterization of selenoproteomes and identification of a Kinetoplastida-specific selenoprotein. Nucleic Acids Res. 34, 4012-4024. doi: 10.1093/nar/gkl541

Lu, J., and Holmgren, A. (2014). The thioredoxin antioxidant system. Free Radic. Biol. Med. 66, 75-87. doi: 10.1016/j.freeradbiomed.2013.07.036

Lu, J., Vlamis-Gardikas, A., Kandasamy, K., Zhao, R., Gustafsson, T. N., Engstrand, L., et al. (2013). Inhibition of bacterial thioredoxin reductase: an antibiotic mechanism targeting bacteria lacking glutathione. FASEB J. 27, 1394-1403. doi: 10.1096/fj.12-223305

Machado, A. K., Morgan, B. A., and Merrill, G. F. (1997). Thioredoxin reductasedependent inhibition of MCB cell cycle box activity in Saccharomyces cerevisiae. J. Biol. Chem. 272, 17045-17054. doi: 10.1074/jbc.272.27.17045

McMillan, P. J., Patzewitz, E. M., Young, S. E., Westrop, G. D., Coombs, G. H., Engman, L., et al. (2009). Differential inhibition of high and low Mr thioredoxin reductases of parasites by organotelluriums supports the concept that low $\mathrm{Mr}$ 
thioredoxin reductases are good drug targets. Parasitology 136, 27-33. doi: $10.1017 /$ S0031182008005131

Miranda-Vizuete, A., Damdimopoulos, A. E., Gustafsson, J., and Spyrou, G. (1997). Cloning, expression, and characterization of a novel Escherichia coli thioredoxin. J. Biol. Chem. 272, 30841-30847. doi: 10.1074/jbc.272.49.30841

Missall, T. A., and Lodge, J. K. (2005). Thioredoxin reductase is essential for viability in the fungal pathogen Cryptococcus neoformans. Eukaryot. Cell 4, 487-489. doi: 10.1128/EC.4.2.487-489.2005

Muller, A., Cadenas, E., Graf, P., and Sies, H. (1984). A novel biologically active seleno-organic compound-I. Glutathione peroxidase-like activity in vitro and antioxidant capacity of PZ 51 (Ebselen). Biochem. Pharmacol. 33, 3235-3239.

Muller, E. G. (1991). Thioredoxin deficiency in yeast prolongs $S$ phase and shortens the G1 interval of the cell cycle. J. Biol. Chem. 266, 9194-9202.

Muller, E. G. (1996). A glutathione reductase mutant of yeast accumulates high levels of oxidized glutathione and requires thioredoxin for growth. Mol. Biol. Cell 7, 1805-1813. doi: 10.1091/mbc.7.11.1805

Muller, E. G., and Buchanan, B. B. (1989). Thioredoxin is essential for photosynthetic growth. The thioredoxin m gene of Anacystis nidulans. J. Biol. Chem. 264, 4008-4014.

Ngo, H. X., Shrestha, S. K., and Garneau-Tsodikova, S. (2016). Identification of ebsulfur analogues with broad-spectrum antifungal activity. ChemMedChem 11, 1507-1516. doi: 10.1002/cmdc.201600236

Nickel, C., Rahlfs, S., Deponte, M., Koncarevic, S., and Becker, K. (2006). Thioredoxin networks in the malarial parasite Plasmodium falciparum. Antioxid. Redox Signal. 8, 1227-1239. doi: 10.1089/ars.2006.8.1227

Pasternak, C., Assemat, K., Clement-Metral, J. D., and Klug, G. (1997). Thioredoxin is essential for Rhodobacter sphaeroides growth by aerobic and anaerobic respiration. Microbiology 143(Pt 1), 83-91. doi: 10.1099/00221287-143-1-83

Pearson, G. D., and Merrill, G. F. (1998). Deletion of the Saccharomyces cerevisiae TRR1 gene encoding thioredoxin reductase inhibits p53-dependent reporter gene expression. J. Biol. Chem. 273, 5431-5434. doi: 10.1074/jbc.273.10.5431

Pedrajas, J. R., Kosmidou, E., Miranda-Vizuete, A., Gustafsson, J. A., Wright, A. P., and Spyrou, G. (1999). Identification and functional characterization of a novel mitochondrial thioredoxin system in Saccharomyces cerevisiae. J. Biol. Chem. 274, 6366-6373. doi: 10.1074/jbc.274.10.6366

Pietka-Ottlik, M., Wojtowicz-Mlochowska, H., Kolodziejczyk, K., Piasecki, E., and Mlochowski, J. (2008). New organoselenium compounds active against pathogenic bacteria, fungi and viruses. Chem. Pharm. Bull. 56, 1423-1427. doi: $10.1248 / \mathrm{cpb} .56 .1423$

Prinz, W. A., Aslund, F., Holmgren, A., and Beckwith, J. (1997). The role of the thioredoxin and glutaredoxin pathways in reducing protein disulfide bonds in the Escherichia coli cytoplasm. J. Biol. Chem. 272, 15661-15667. doi: 10.1074/ jbc.272.25.15661

Ramanathan, R. K., Abbruzzese, J., Dragovich, T., Kirkpatrick, L., Guillen, J. M., Baker, A. F., et al. (2011). A randomized phase II study of PX-12, an inhibitor of thioredoxin in patients with advanced cancer of the pancreas following progression after a gemcitabine-containing combination. Cancer Chemother. Pharmacol. 67, 503-509. doi: 10.1007/s00280-010-1343-8

Reichard, P. (1993). The anaerobic ribonucleotide reductase from Escherichia coli. J. Biol. Chem. 268, 8383-8386.

Ritz, D., Patel, H., Doan, B., Zheng, M., Aslund, F., Storz, G., et al. (2000). Thioredoxin 2 is involved in the oxidative stress response in Escherichia coli. J. Biol. Chem. 275, 2505-2512. doi: 10.1074/jbc.275.4.2505

Roos, G., Foloppe, N., Van Laer, K., Wyns, L., Nilsson, L., Geerlings, P., et al. (2009). How thioredoxin dissociates its mixed disulfide. PLoS Comput. Biol. 5:e1000461. doi: 10.1371/journal.pcbi.1000461

Ross, F., Hernandez, P., Porcal, W., Lopez, G. V., Cerecetto, H., Gonzalez, M., et al. (2012). Identification of thioredoxin glutathione reductase inhibitors that kill cestode and trematode parasites. PLoS One 7:e35033. doi: 10.1371/journal.pone. 0035033

Russel, M., Model, P., and Holmgren, A. (1990). Thioredoxin or glutaredoxin in Escherichia coli is essential for sulfate reduction but not for deoxyribonucleotide synthesis. J. Bacteriol. 172, 1923-1929. doi: 10.1128/jb.172.4.1923-1929.1990

Sannella, A. R., Casini, A., Gabbiani, C., Messori, L., Bilia, A. R., Vincieri, F. F., et al. (2008). New uses for old drugs. Auranofin, a clinically established antiarthritic metallodrug, exhibits potent antimalarial effects in vitro: mechanistic and pharmacological implications. FEBS Lett. 582, 844-847. doi: 10.1016/j.febslet. 2008.02.028
Scharf, C., Riethdorf, S., Ernst, H., Engelmann, S., Volker, U., and Hecker, M. (1998). Thioredoxin is an essential protein induced by multiple stresses in Bacillus subtilis. J. Bacteriol. 180, 1869-1877.

Schewe, T. (1995). Molecular actions of ebselen-an antiinflammatory antioxidant. Gen. Pharmacol. 26, 1153-1169. doi: 10.1016/0306-3623(95)00003-J

Siles, S. A., Srinivasan, A., Pierce, C. G., Lopez-Ribot, J. L., and Ramasubramanian, A. K. (2013). High-throughput screening of a collection of known pharmacologically active small compounds for identification of Candida albicans biofilm inhibitors. Antimicrob. Agents Chemother. 57, 3681-3687. doi: 10.1128/AAC.00680-13

Singh, N., Sharpley, A. L., Emir, U. E., Masaki, C., Herzallah, M. M., Gluck, M. A., et al. (2016). Effect of the putative lithium mimetic ebselen on brain MyoInositol, sleep, and emotional processing in humans. Neuropsychopharmacology 41, 1768-1778. doi: 10.1038/npp.2015.343

Stewart, E. J., Aslund, F., and Beckwith, J. (1998). Disulfide bond formation in the Escherichia coli cytoplasm: an in vivo role reversal for the thioredoxins. EMBO J. 17, 5543-5550. doi: 10.1093/emboj/17.19.5543

Tejman-Yarden, N., Miyamoto, Y., Leitsch, D., Santini, J., Debnath, A., Gut, J., et al. (2013). A reprofiled drug, auranofin, is effective against metronidazoleresistant Giardia lamblia. Antimicrob. Agents Chemother. 57, 2029-2035. doi: 10.1128/AAC.01675-12

Thangamani, S., Eldesouky, H. E., Mohammad, H., Pascuzzi, P. E., Avramova, L., Hazbun, T. R., et al. (2017a). Ebselen exerts antifungal activity by regulating glutathione (GSH) and reactive oxygen species (ROS) production in fungal cells. Biochim. Biophys. Acta 1861(1 Pt A), 3002-3010. doi: 10.1016/j.bbagen. 2016.09.029

Thangamani, S., Maland, M., Mohammad, H., Pascuzzi, P. E., Avramova, L., Koehler, C. M., et al. (2017b). Repurposing approach identifies auranofin with broad spectrum antifungal activity that targets Mia40-Erv1 pathway. Front. Cell. Infect. Microbiol. 7:4. doi: 10.3389/fcimb.2017.00004

Thangamani, S., Mohammad, H., Abushahba, M. F., Sobreira, T. J., Hedrick, V. E., Paul, L. N., et al. (2016a). Antibacterial activity and mechanism of action of auranofin against multi-drug resistant bacterial pathogens. Sci. Rep. 6:22571. doi: 10.1038/srep22571

Thangamani, S., Mohammad, H., Abushahba, M. F., Sobreira, T. J., and Seleem, M. N. (2016b). Repurposing auranofin for the treatment of cutaneous staphylococcal infections. Int. J. Antimicrob. Agents 47, 195-201. doi: 10.1016/j. ijantimicag.2015.12.016

Thangamani, S., Younis, W., and Seleem, M. N. (2015). Repurposing ebselen for treatment of multidrug-resistant staphylococcal infections. Sci. Rep. 5:11596. doi: 10.1038/srep11596

Theobald, A. J., Caballero, I., Coma, I., Colmenarejo, G., Cid, C., Gamo, F. J., et al. (2012). Discovery and biochemical characterization of Plasmodium thioredoxin reductase inhibitors from an antimalarial set. Biochemistry 51, 4764-4771. doi: 10.1021/bi3005076

Thon, M., Al-Abdallah, Q., Hortschansky, P., and Brakhage, A. A. (2007). The thioredoxin system of the filamentous fungus Aspergillus nidulans: impact on development and oxidative stress response. J. Biol. Chem. 282, 27259-27269. doi: 10.1074/jbc.M704298200

Torres, N. S., Abercrombie, J. J., Srinivasan, A., Lopez-Ribot, J. L., Ramasubramanian, A. K., and Leung, K. P. (2016). Screening a commercial library of pharmacologically active small molecules against Staphylococcus aureus biofilms. Antimicrob. Agents Chemother. 60, 5663-5672. doi: 10.1128/AAC.00377-16

Wassmann, C., Hellberg, A., Tannich, E., and Bruchhaus, I. (1999). Metronidazole resistance in the protozoan parasite Entamoeba histolytica is associated with increased expression of iron-containing superoxide dismutase and peroxiredoxin and decreased expression of ferredoxin 1 and flavin reductase. J. Biol. Chem. 274, 26051-26056. doi: 10.1074/jbc.274.37. 26051

Wiederhold, N. P., Patterson, T. F., Srinivasan, A., Chaturvedi, A. K., Fothergill, A. W., Wormley, F. L., et al. (2017). Repurposing auranofin as an antifungal: in vitro activity against a variety of medically important fungi. Virulence 8, 138-142. doi: 10.1080/21505594.2016.1196301

Williams, C. H., Arscott, L. D., Muller, S., Lennon, B. W., Ludwig, M. L Wang, P. F., et al. (2000). Thioredoxin reductase two modes of catalysis have evolved. Eur. J. Biochem. 267, 6110-6117. doi: 10.1046/j.1432-1327.2000. 01702.x 
Windle, H. J., Fox, A., Ni Eidhin, D., and Kelleher, D. (2000). The thioredoxin system of Helicobacter pylori. J. Biol. Chem. 275, 5081-5089. doi: 10.1074/jbc. 275.7.5081

Xue, J., Jiang, W., Chen, Y., Gong, F., Wang, M., Zeng, P., et al. (2017). Thioredoxin reductase from Toxoplasma gondii: an essential virulence effector with antioxidant function. FASEB J. 31, 4447-4457. doi: 10.1096/fj.20170 0008R

Zaki, N. Z., Bakar, F. D. A., Mahadi, N. M., and Murad, A. M. A. (2012). Candida albicans TRR1 heterozygotes show increased sensitivity to oxidative stress and decreased pathogenicity. Afr. J. Microbiol. Res. 6, 1796-1805. doi: 10.5897/ Ajmr11.1295

Zeller, T., and Klug, G. (2006). Thioredoxins in bacteria: functions in oxidative stress response and regulation of thioredoxin genes. Naturwissenschaften 93, 259-266. doi: 10.1007/s00114-0060106-1

Zhang, Z., Bao, R., Zhang, Y., Yu, J., Zhou, C. Z., and Chen, Y. (2009). Crystal structure of Saccharomyces cerevisiae cytoplasmic thioredoxin reductase Trrl reveals the structural basis for species-specific recognition of thioredoxin. Biochim. Biophys. Acta 1794, 124-128. doi: 10.1016/j.bbapap.2008. 09.011

Zou, L., Lu, J., Wang, J., Ren, X., Zhang, L., Gao, Y., et al. (2017). Synergistic antibacterial effect of silver and ebselen against multidrug-resistant Gramnegative bacterial infections. EMBO Mol. Med. 9, 1165-1178. doi: 10.15252/ emmm.201707661

Conflict of Interest Statement: The authors declare that the research was conducted in the absence of any commercial or financial relationships that could be construed as a potential conflict of interest.

Copyright (C) 2018 May, Yu, Guentzel, Chambers, Cap and Arulanandam. This is an open-access article distributed under the terms of the Creative Commons Attribution License (CC BY). The use, distribution or reproduction in other forums is permitted, provided the original author(s) and the copyright owner are credited and that the original publication in this journal is cited, in accordance with accepted academic practice. No use, distribution or reproduction is permitted which does not comply with these terms. 